\title{
$\infty$
}

\section{Effect of Annealing Temperature on the Properties of Sputtered $\mathrm{Bi}_{3.25} \mathrm{La}_{0.75} \mathrm{Ti}_{3} \mathrm{O}_{12}$ Thin Films}

\author{
Hyunil Kang ${ }^{\dagger}$ \\ Department of Electrical Engineering, Hanbat National University, Daejeon 305-719, Korea \\ Joontae Song \\ School of Information and Communication Engineering, Sungkyunkwan University, Suwon 440-746, Korea
}

Received November 26, 2012; Revised December 17, 2012; Accepted March 4, 2013

\begin{abstract}
$\mathrm{Bi}_{3.25} \mathrm{La}_{0.75} \mathrm{Ti}_{3} \mathrm{O}_{12}$ (BLT) thin films were prepared on the $\mathrm{Pt}(150 \mathrm{~nm}) / \mathrm{Ti}(50 \mathrm{~nm}) / \mathrm{SiO}_{2} / \mathrm{Si}$ substrate using the rf magnetron sputtering method. The BLT thin films were annealed at temperatures ranging from $600{ }^{\circ} \mathrm{C}$ to $750^{\circ} \mathrm{C}$ using the rapid thermal annealing. The structure and surface morphology of the thin films were characterized by $\mathrm{x}$-ray diffraction and field emission scanning electron microscopy. The hysteresis loop of the BLT thin films showed that the remanent polarization (2Pr) of the film annealed at $700{ }^{\circ} \mathrm{C}$ was $10.92 \mu \mathrm{C} / \mathrm{cm}^{2}$. The fatigue characteristic of the BLT thin film annealed at $700^{\circ} \mathrm{C}$ was shown change polarization up to $1.2 \times 10^{9}$ switching cycles. We confirmed the excellent remnant polarization (Pr) and fatigue properties compared with other fabrication methods and suggested a good method for BLT thin films fabrications.
\end{abstract}

Keywords: Annealing temperature, BLT, Ferroelectric, Fatigue

\section{INTRODUCTION}

T. W. Noh et al. reported that BLT thin films provide a promising alternative for ferroelectrics random access memory (FRAM) applications by the pulse laser deposition (PLD) method [1]. The merits can be deposited at low temperature $\left(<650^{\circ} \mathrm{C}\right)$ and the films were fatigue free on metal electrodes. In order to improve the electrical properties, several deposition techniques were being tried for the growth of BLT thin films. M.C. Kao et al reported that the films showed improvement of electrical properties using the sol-gel method [2]. The excellent fatigue property up to 1010 cycles by the metal organic deposition (MOD) method was reported $[3,4]$. A.Z. Simões et al. reported that orientations mainly contributed to electrical properties using metal organic chemical vapor deposition (MOCVD) [5].

${ }^{\dagger}$ Author to whom all correspondence should be addressed:

E-mail: hikang@hanbat.ac.kr

Copyright $\odot 2013$ KIEEME. All rights reserved.

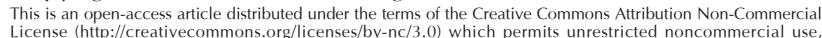
License
distribution, and reproduction in any medium, provided the original work is properly cited
N. Zhong et al. reported the effect of La doping on the improvement of structural and electrical properties using chemical solution deposition (CSD) [6]. In this study, we fabricated BLT thin films by the rf magnetron sputtering method and found the improvement on electrical properties of the films fabricated by the rf magnetron sputtering method with a single stoichiometric target. We confirmed the excellent remnant polarization $(\mathrm{Pr})$ and suggested a good method for BLT thin films fabrication.

\section{EXPERIMENTS}

BLT thin films with a thickness of $200 \mathrm{~nm}$ were deposited on a Pt $(150 \mathrm{~nm}) / \mathrm{Ti}(50 \mathrm{~nm}) / \mathrm{SiO}_{2} / \mathrm{Si}$ substrate by rf magnetron sputtering. The as-deposited BLT thin films were annealed at temperatures ranging from $650^{\circ} \mathrm{C}$ to $750^{\circ} \mathrm{C}$ in oxygen atmosphere for 5 min using rapid thermal annealing (RTA). The crystal structure of the BLT thin films were analyzed using X-ray diffraction (XRD, Mac Science M18XHFSRA, Cu target, 1.54 $\AA$, Ni filter). The XRD patterns were recorded at a scan rate of $5^{\circ}$ per minute for the crystal structure analysis. The surface morphology of the 
sputtered BLT thin film was observed using a scanning electron microscope (SEM, JEOL JSM6700F). In order to estimate the dielectric and ferroelectric properties, Pt dot electrodes of 0.3 $\mathrm{mm}^{2}$ in diameter were patterned by the shadow mask sputtering process. The leakage current behavior of BLT capacitors was obtained using a Keithley 617 programmable electrometer. The dielectric properties of the BLT capacitors were measured by a multi-frequency LCR meter (Boonton 7200). The ferroelectric polarization versus the electric field (P-E) hysteresis loops and fatigue properties of the fabricated BLT capacitors were measured using an RT66A ferroelectric tester (Radiant Technologies Inc) in the virtual ground mode.

\section{RESULTS AND DISCUSSION}

Figure 1 shows the X-ray patterns for BLT thin films deposited on the Pt/Ti electrode annealed by RTA at various temperatures ranging from $650^{\circ} \mathrm{C}$ to $750^{\circ} \mathrm{C}$. BLT thin films annealed at $700^{\circ} \mathrm{C}$ had the strongest (006) peak intensity in the XRD pattern of BLT thin films. With further increase in annealing temperature, (117) peaks became increasingly sharp and increased for temperatures from $600{ }^{\circ} \mathrm{C}$ to $700^{\circ} \mathrm{C}$ and decreased at $750^{\circ} \mathrm{C}$. The Lotgering degree of a-axis and c-axis orientation was evaluated according to the following equation, respectively [7]:

$$
\begin{aligned}
& \text { a-axis orientation }=\frac{I_{117}}{I_{006}+I_{117}} \\
& \text { c-axis orientation }=\frac{I_{006}}{I_{006}+I_{117}}
\end{aligned}
$$

where $\mathrm{I}_{006}$ and $\mathrm{I}_{117}$ are the measured XRD peak intensities of (006) and (117), respectively. As the result of Lotgering evaluation, the degree of a-axis orientation for $650^{\circ} \mathrm{C}, 700^{\circ} \mathrm{C}$ and $750^{\circ} \mathrm{C}$ are estimated to be $77.3 \%, 57.7 \%$ and $54.7 \%$, respectively. These results indicate that the BLT thin films annealed at $650^{\circ} \mathrm{C}$ have an enhanced a-axis orientation. The c-axis orientation growth of BLT thin films is mainly determined by the interfacial energy state of BLT thin films and the substrate. The interfacial energy is related to the atomic plane density in the interface between the BLT thin films and substrate [6]. The degree of c-axis orientation for $650^{\circ} \mathrm{C}, 700^{\circ} \mathrm{C}$ and $750^{\circ} \mathrm{C}$ are estimated to be $22.6 \%, 44.3 \%$ and $45.2 \%$, respectively. It is found that the c-axis orientation of the BLT thin film above $700^{\circ} \mathrm{C}$ has the highest atomic plane density and the lowest interracial energy.

Figure 2 presents the SEM surface micrographs of the sputtered BLT thin films after 5 min RTA annealing with different temperatures. The surface micrograph is shown to be highly sensitive to the RTA annealing temperature. As-grown BLT thin film in Fig. 2 (a) shows the fine-grained thin film due to the poor crystallization. As the annealing temperature increased from $650^{\circ} \mathrm{C}$ to $750^{\circ} \mathrm{C}$, the crystallized fraction of the films increased as well. Also, the average grain size of the BLT thin films increased with annealing temperature. With increasing RTA temperature at $700^{\circ} \mathrm{C}$, we observed the plate-like grain morphology and uniform grain sizes. These results indicate that the ferroelectric properties of the BLT thin films can be improved by increasing the annealing temperature [2].

The leakage current density of the BLT thin films was studied at different temperatures. The leakage current against electric field curves of the BLT capacitors was shown in Fig. 3. The leakage current density of the annealed BLT thin films at $650^{\circ} \mathrm{C}$, $700^{\circ} \mathrm{C}$ and $750^{\circ} \mathrm{C}$ were measured with $3.56 \times 10^{-7} \mathrm{~A} / \mathrm{cm}^{2}, 2.62 \times$ $10^{-6} \mathrm{~A} / \mathrm{cm}^{2}$ and $4.83 \times 10^{-5} \mathrm{~A} / \mathrm{cm}^{2}$ at the $125 \mathrm{kV} / \mathrm{cm}$, respectively.

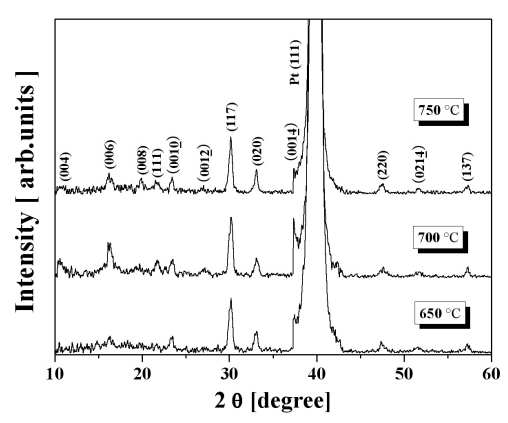

Fig. 1. X-ray diffraction pattern of $\mathrm{Bi}_{3.25} \mathrm{La}_{0.75} \mathrm{Ti}_{3} \mathrm{O}_{12}$ thin films post annealed.

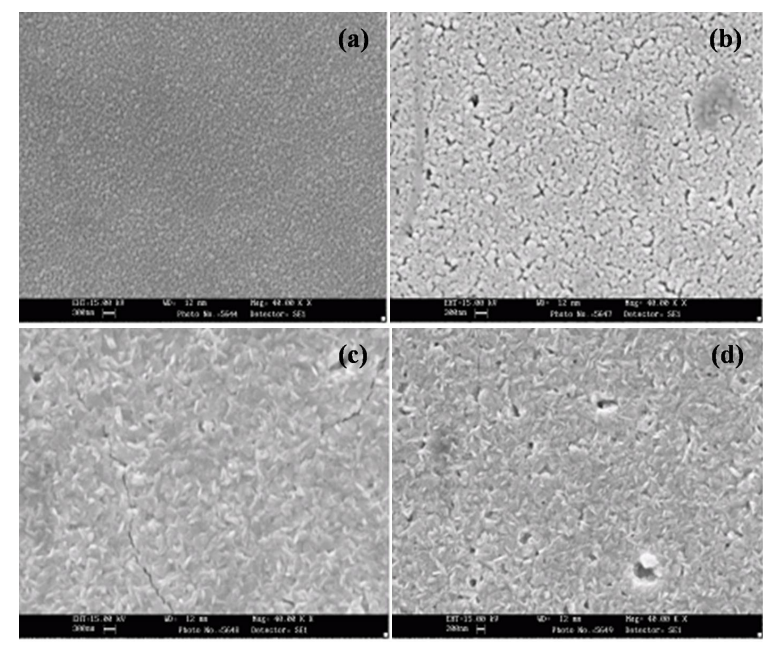

Fig. 2. SEM surface images of $\mathrm{Bi}_{3.25} \mathrm{La}_{0.75} \mathrm{Ti}_{3} \mathrm{O}_{12}$ thin films post-annealed for (a) as-grown, (b) $650^{\circ} \mathrm{C}$, (c) $700^{\circ} \mathrm{C}$, and (d) $750^{\circ} \mathrm{C}$.

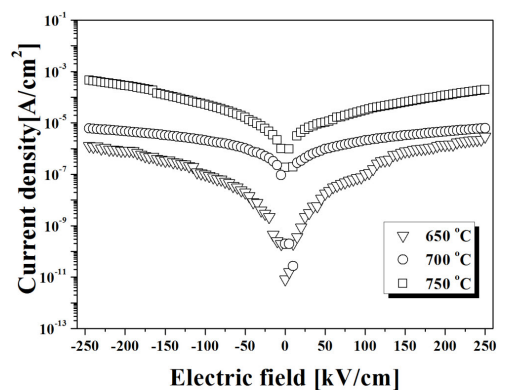

Fig. 3. The leakage current density of the annealed BLT thin films at $650^{\circ} \mathrm{C}, 700^{\circ} \mathrm{C}$, and $750^{\circ} \mathrm{C}$.

The leakage current of BLT thin films at $650^{\circ} \mathrm{C}$ exhibit asymmetry. When the annealing temperature was increased, the leakage current densities were increased. The increase of leakage current density is due to several defects such as bismuth vacancies and oxygen vacancies [8].

Figure 4 shows the P-E hysteresis curves of BLT thin films with various temperatures. As is known, the dielectric and ferroelectric properties are strongly influenced by grain size, porosity, film thickness and growth conditions of BLT thin films. In general, the dielectric constant and remnant polarization increases while the coercive field decreases for thin films with large grain size. The remnant polarization values $(\mathrm{Pr})$ of the samples post-annealed at $650^{\circ} \mathrm{C}, 700^{\circ} \mathrm{C}$ and $750^{\circ} \mathrm{C}$ were measured with $5.42 \mu \mathrm{C} / \mathrm{cm}^{2}, 10.92$ 


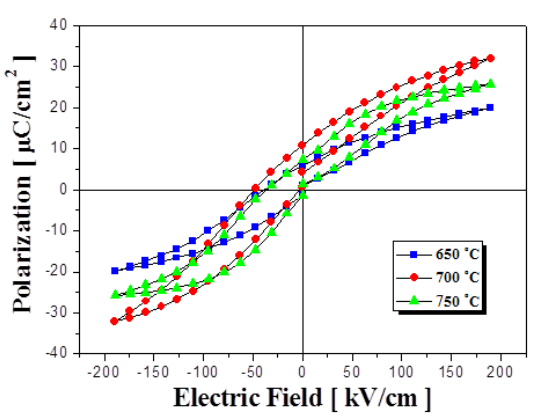

Fig. 4. P-E hysteresis curves of BLT thin films with various temperatures.

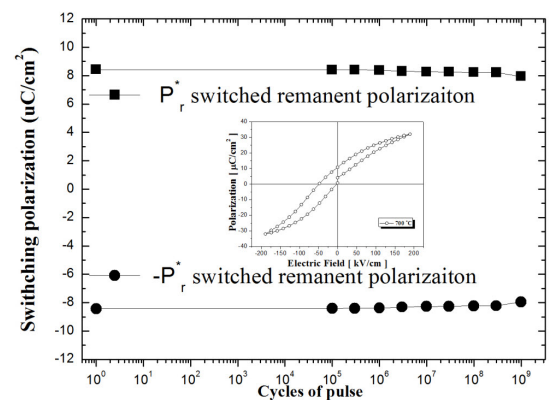

Fig. 5. Ferroelectric fatigue characteristic of BLT thin films postannealed at $700^{\circ} \mathrm{C}$.

$\mu \mathrm{C} / \mathrm{cm}^{2}$ and $7.76 \mu \mathrm{C} / \mathrm{cm}^{2}$, respectively. The coercive field (Ec) of the BLT films increases with the increase of annealing temperature from $650^{\circ} \mathrm{C}$ to $700^{\circ} \mathrm{C}$, and then decreases with the increase of annealing temperature from $700^{\circ} \mathrm{C}$ to $750^{\circ} \mathrm{C}$. The annealed BLT thin film at $650^{\circ} \mathrm{C}$ demonstrates a coercive field of $56 \mathrm{kV} / \mathrm{cm}$, while a coercive field decreases to $46 \mathrm{kV} / \mathrm{cm}$ in the annealed BLT thin film at $700{ }^{\circ} \mathrm{C}$. These results indicate that domains can switch more easily in BLT thin films annealed at temperatures above $700^{\circ} \mathrm{C}$. It can be described in terms of the effect of the grain size and the stress induced by the substrate.

The fatigue property is an important parameter to characterize the ferroelectric random access memory. The fatigue property of the ferroelectric thin films is characterized by the loss of switchable polarization with repeated switching cycles. The loss of switchable polarization constrains the life time of the ferroelectric memory. The loss of switchable polarization reduces the ability to differentiate the two remanent polarizations until they become indistinguishable [9].
Ferroelectric fatigue characteristic of BLT thin films postannealed at $700^{\circ} \mathrm{C}$ was illustrated in Fig. 5. There were no significant losses in remnant polarization up to $1.2 \times 10^{9}$ cycles and the measured results were in agreement with those of other fabrication methods.

\section{CONCLUSIONS}

In this study, BLT thin films were successfully fabricated on $\mathrm{Pt} / \mathrm{Ti} / \mathrm{SiO}_{2} / \mathrm{Si}$ by the rf magnetron sputtering method. It was observed that sputtered BLT thin films showed lower leakage current and higher ferroelectric properties compared to other fabrication methods. The thin films showed to be fatigue free, maintaining the value of the remnant polarization $(10.92 \mu \mathrm{C} /$ $\mathrm{cm}^{2}$ ) up to $1.2 \times 10^{9}$ cycles. From these results, we suggested a method for the application of next-generation memory devices by rf magnetron sputtering.

\section{ACKNOWLEDGMENTS}

This work was supported by Hanbat national university research grant of 2011.

\section{REFERENCES}

[1] B. H. Park, B. S. Kang, S. D. Bu, T. W. Noh, J. Lee, and W. Jo, Nature 401, 682 (1999) [DOI: http://dx.doi.org/10.1038/44352].

[2] M. C. Kao, H. Z. Chen, S. L. Young, Mater. Lett. 62, 629 (2008) [DOI: http://dx.doi.org/10.1016/j.matlet.2007.06.023].

[3] K. T. Kim, C. I. Kim, Thin Solid Films. 478, 6 (2005) [DOI: http:// dx.doi.org/10.1016/j.tsf.2004.09.042].

[4] H. H. Park, H. S. Lee, H. H. Park, R. H. Hill, Y. T. Hwang, Appl. Surf. Sci. 255, 4197 (2009) [DOI: http://dx.doi.org/10.1016/ j.apsusc.2008.11.011].

[5] A. Z. Simões, E. C. Aguiar, C. S. Riccardi, E. Longo, J. A. Varela, Mater. Charact. 78, 353 (2009) [DOI: http://dx.doi.org/10.1016/ j.matchar.2008.09.015].

[6] N. Zhong, T. Shiosaki, Mater. Lett. 61, 2935 (2007) [DOI: http:// dx.doi.org/10.1016/j.matlet.2006.10.046].

[7] X. L. Fang, B. Shen, J. W. Zhai, X. Yao, Ceram. Int. 38, S83 (2012). [DOI: http://dx.doi.org/10.1016/j.ceramint.2011.04.055].

[8] A. Z. Simoes, M. A. Ramirez, E. Longo and J. A. Varela, Mater. Chem. Phys. 107, 72 (2008) [DOI: http://dx.doi.org/10.1016/ j.matchemphys.2007.06.043].

[9] J. S. Lee, B. S. Kang, and Q. X. Jia, Appl. Phys. Lett. 91, 142901 (2007) [DOI: http://dx.doi.org/10.1063/1.2780118]. 